\title{
Mild phosphoribosylpyrophosphate synthetase superactivity
}

INSERM

\section{Source}

INSERM. (1999). Orphanet: an online rare disease and orphan drug data base. Mild phosphoribosylpyrophosphate synthetase superactivity. ORPHA:411536

Mild phosphoribosylpyrophosphate (PRPP) synthetase superactivity is the mild and lateonset form of PRPP synthetase superactivity (see this term), an X-linked disorder of purine metabolism associated with hyperuricemia and hyperuricosuria, leading to urolithiasis and gout. This form is not associated with any neuropathy or central nervous system (CNS) disorders. 